\title{
Generation of SPWM Control Pulses for ZSI Using dsPIC33EP256MU810
}

${ }^{* 1}$ Punam C. Moundekar, ${ }^{2}$ Gaurav Goyal, ${ }^{3}$ Dr. M. M Renge

Department of Electrical Engineering, Shri Ramdeobaba College of Engineering and Management Nagpur, India Email: *pmoundekar94gmail.com,goyalg@rknec.edu,rengemm@rknec.edu

Received: $20^{\text {th }}$ September2018, Accepted: $11^{\text {th }}$ October 2018, Published: $31^{\text {st }}$ October 2018

\begin{abstract}
The aim of this paper is to present the design and implementation of an algorithm for controlling a 3-phase Z-source inverter (ZSI) using a digital signal controller (DSC), the complexity arises due to analog circuit can be eliminated by DSC algorithm also reduces cost, size of filter required, and improved overall inverter efficiency. In this paper, the power inverter i.e. ZSI are controlled by high performance dsPIC33EP256MU810 DSC that can achieve high-level inverter control, therefore this DSC is the heart of the system and it controls entire system. The DSC is programmed using embedded MPLAB software and it generates sinusoidal pulse width modulated (SPWM) pulses for ZSI for simple boost control and maximum constant boost control. To validate the proposed algorithm of ZSI MATLAB simulation and experimental results are presented.
\end{abstract}

\section{Keywords}

dsPIC33EP256MU810, Maximum Constant Boost Control (MCBC), Sinusoidal Pulse Width Modulation (SPWM), Simple Boost Control (SBC), Voltage Source Inverter (VSI), Z-Source Inverter (ZSI).

\section{Introduction}

In the present situation, electricity plays a major role in day to day life. There is a peak demand of power supply. But during the case of power outage, power electronic devices like inverters play the major role to provide the continuous supply to the system. Therefore it is necessary to design the power inverter with low cost and higher efficiency. By using the power inverter DC power is converter to AC power at required output voltage and frequency. The power inverter is significantly used in hybrid power system and micro-grid system. The variable frequency \& variable voltage supply is needed in industrial applications, such as single phase and three Phase Induction Motor \& other rotating machines therefore, to vary the supply frequency and supply voltage, Voltage Source Inverter (VSI) is used [1-2]. Various new PWM techniques are developed for efficient power utilization. Now a day's many types of pulse width modulating techniques have been proposed such as, Sinusoidal PWM (SPWM), Space Vector PWM (SVPWM), Selective Harmonic Elimination PWM (SHEPWM). However, these methods have some advantages as well as disadvantages. But in industry standard, the SPWM has proved to be most potential technique among all others. The SPWM technique for generating a fundamental sine wave that provides a higher voltage to the motor has lower total harmonic distortion (THD) [3]. However, these traditional voltage source inverters have conceptual and theoretical barriers and limitations as indicated in [4]. Therefore, to overcome these limitations of Voltage Source Inverter (VSI) new topology had been proposed known as Z-source inverter (ZSI).

New kind of inverter in power conversion, impedance-source inverter also referred as Z-source inverter (ZSI) had been proposed by F. Z. Peng [4]. The ZSI is an emerging topology for power electronics dc-ac converters. In this topology, by utilizing the shoot-through (ST) zero state input voltage can be boosted, which improves the inverter reliability and enlarges its application field. In comparison with other power electronic converters, it provides an attractive single-stage dc-ac conversion with buck-boost capability, reduced cost, reduced volume, and higher efficiency due to a lower switching component of buck-boost circuit.

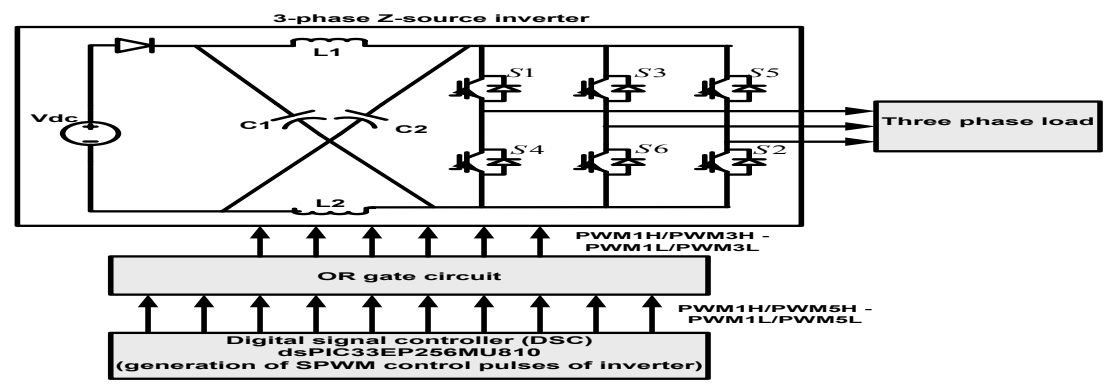

Figure 1: Block Diagram Representation of 3-Phase Z-Source Inverter 
Therefore, the ZSI is a very promising and competitive topology for renewable energy sources, such as fuel cells, photovoltaic arrays, wind turbines, and new power electronics applications, such as electric and hybrid vehicles. Different control methods for operating ZSI had been proposed [4-11], which are simple boost control (SBC) [4], maximum boost control (MBC) [9] and maximum constant boost control (MCBC) [10]. In this paper simple boost control (SBC) and maximum constant boost control (MCBC) methods have been used for generating the control pulses of ZSI.

In this paper dsPIC33EP256MU810 has been used for three phase PWM generation and inverter control. The main objective of this paper is to design the control algorithm of three phase Z-source inverter using sinusoidal Pulse Width Modulation (SPWM) technique with simple boost and maximum constant boost in dsPIC33EP256MU810 using embedded MPLAB software. The block diagram representation of 3-phase Z-source inverter is shown in Figure 1.

\section{Introduction of DSC}

In the recent trend, the requirement of embedded systems is increasing very rapidly. It has high computational requirements and in most of the cases limited resources available in embedded systems. This high-performance Digital Signal Processors (DSPs) have additional features to address multi-media needs therefore, it is very necessary to understand these all features and its real-time vision-based applications [12-17].

Microchip's dsPIC33E family of digital signal controller (DSCs) features a 70MIPS DSC core with integrated DSP and enhanced on-chip peripherals. These DSCs is used for controlling the operation of high-performance, precision motor that are more energy efficient, quieter in operation, have a great range and extended life. They can also be applied to control brushless DC, permanent magnet synchronous, AC induction and stepper motors and it is also used for high performance general purpose applications [16.b]. DSC dsPIC 33E operates between $3.0 \mathrm{~V}$ to $3.6 \mathrm{~V}$ for $-40^{\circ} \mathrm{C}$ to $+125^{\circ} \mathrm{C}$ temperature with a speed up to $60 \mathrm{MIPS}$ and between $3.0 \mathrm{~V}$ to $3.6 \mathrm{~V}$ for $-40^{\circ} \mathrm{C}$ to $+85^{\circ} \mathrm{C}$ temperature with a speed up to 70 MIPS. The dsPIC33EP256MU810 DSC has been selected for controlling the proposed inverters. The pin configuration of dsPIC33EP256MU810 IC is shown in Figure 2. It is a 100 pin IC which include on-chip flash program space (up to 280 (Kbyte), flash auxiliary memory (up to $28 \mathrm{Kbytes}$ ) and maximum 60 (MIPS) processor speed.

\section{Proposed Work}

The main objective of this paper is to run the 3-phase ZSI by the control pulses generated by dsPIC33EP256M810 DSC. The proposed control algorithm flow chart of Z-source inverter with SBC and MCBC control techniques is explained in this section. In SBC controlling technique, for creating the shoot through zero states two straight lines are employed (Vp and $\mathrm{Vn}$ ) whereas in MCBC technique two straight lines ( $\mathrm{Vp}$ and $\mathrm{Vn}$ ) are replaced by upper and lower envelope curve of modulating sine waves $\left(\mathrm{V}_{\mathrm{a}}{ }^{*}, \mathrm{~V}_{\mathrm{b}}{ }^{*}, \mathrm{~V}_{\mathrm{c}}{ }^{*}\right)$, respectively. Now, these waves are compared with high- frequency carrier wave. When the carrier waveform is greater than the upper envelope curve (Vp) or smaller than the lower envelope curve (Vn) of references then only shoot through gets generated. The controlling waveforms of 3-phase ZSI for these two techniques are shown in Figure 3. Following steps are involved for generation of SPWM control pulses in dsPIC33EP256MU810 for 3-Phase ZSI. Flow chart representation of DSC programming is shown in Figure 4.

After execution of this program desired control pulses of 3-phase Z-source inverter are obtained at PWM output pins of ICs and this control pulses are fed to OR gate circuit for providing shoot through zero state, and output of OR gate are given to gate signal of switching devices of ZSI.

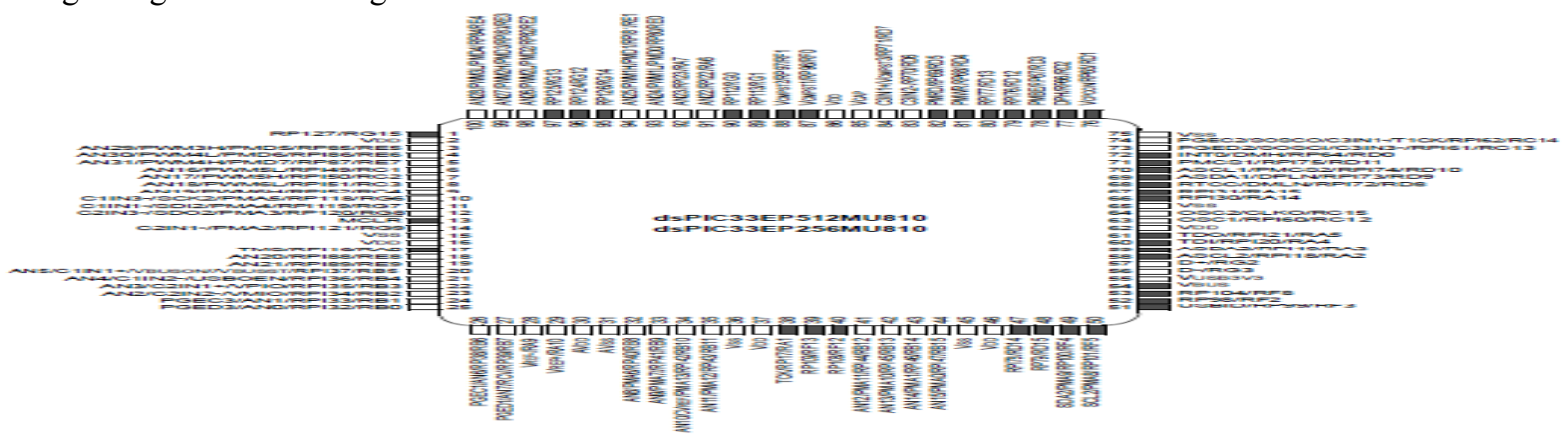

Figure 2: Pin Configuration of dsPIC33EP256MU810 


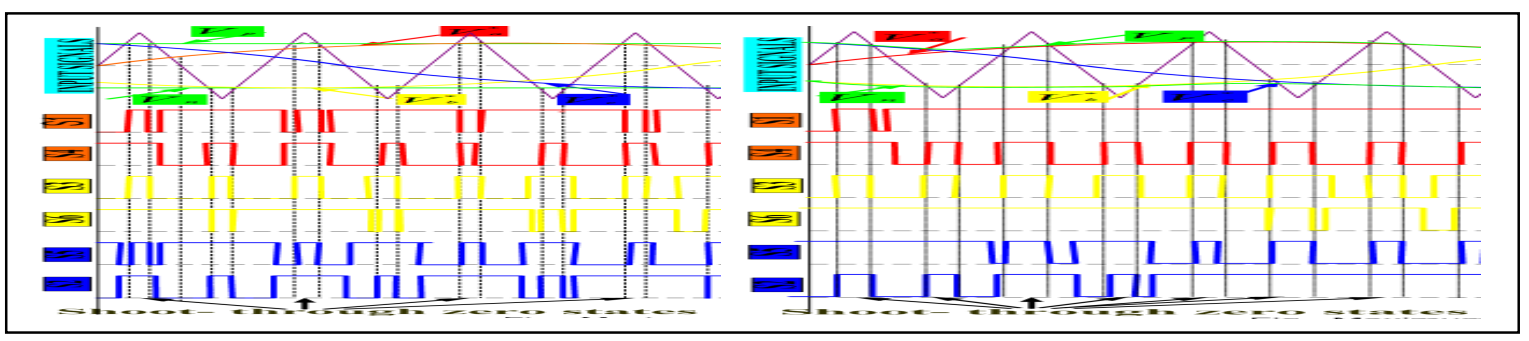

(a)

(b)

Figure 3: SPWM Controlling Waveform for 3-Phase ZSI (a) SBC \& (b) MCBC

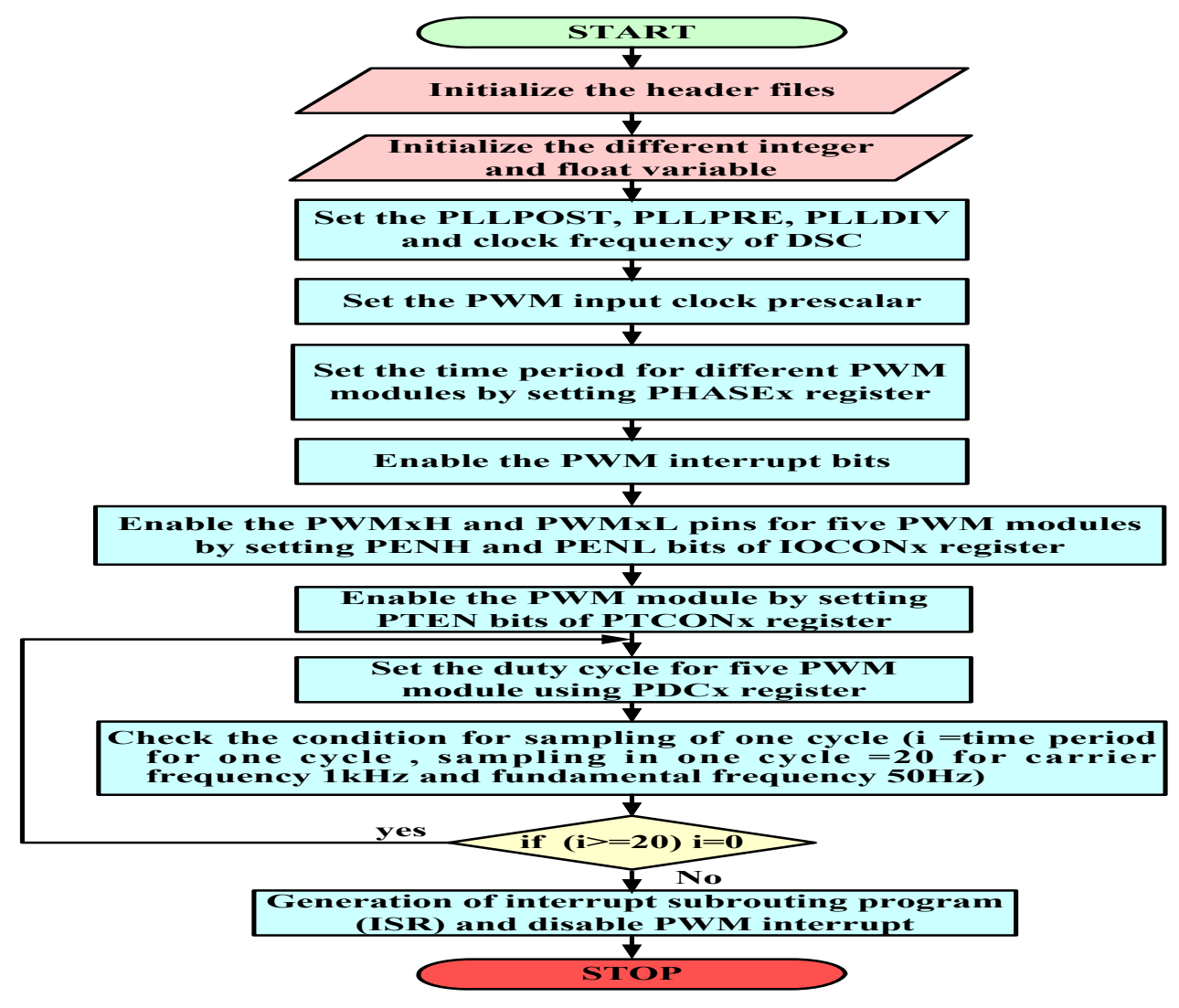

Figure 4: Flowchart Representation of DSC Programming

\section{Simulation and Experimental Results}

To investigate the performance of 3-phase ZSI, simulation was conducted in MATLAB. Simulation results and their relevant waveforms have been presented. The prototype of ZSI is built and its block diagram representation is shown in Fig 1. Experiment is carried out at low voltage in laboratory and TPS2024B four channel DSO has been used for capturing the experimental waveforms of ZSI. The simulated and experimental parameters of ZSI are shown in Table 1. A typical oscilloscope snapshot of the control pulses that outputted from the DSC for the six switches S1- S4 (R-phase), S3-S6 (Yphase), and S5-S2 (B-phase) is shown in Figure 5. This DSC outputs after passing through buffer and driver circuit, are given to switching devices of 3-Phase ZSI. The simulated and experimental line voltages and phase voltages of 3-phase ZSI for SBC and MCBC are shown in Figure 6 and 8 respectively.

In both the methods $\mathrm{DC}$ voltage is $10 \mathrm{~V}$ and we have considered modulation index $=0.8$ and switching frequency is $1 \mathrm{kHz}$, from above analysis we have the following theoretical calculations.

Boost factor, $\mathrm{B}=\frac{1}{2 \mathrm{M}-1}=1.666$ (for $\mathrm{SBC}$ ) or $\frac{1}{\sqrt{3} \mathrm{M}-1}=2.593$ (for $\mathrm{MCBC}$ ) 
Fundamental phase peak voltage of ZSI is:

$\mathrm{V}_{\mathrm{Ph}}=\mathrm{MB} \times \frac{\mathrm{V}_{\mathrm{dc}}}{2}=6.64 \mathrm{~V}$ (for SBC) or $10.372 \mathrm{~V}$ (for $\mathrm{MCBC}$ )

The fundamental peak voltage of ZSI is shows in equation (2), which implicates that the phase RMS voltage is $4.69 \mathrm{~V}$ rms (for $\mathrm{SBC}$ ) or $7.334 \mathrm{~V} \mathrm{rms} \mathrm{(for} \mathrm{MCBC)} \mathrm{and} \mathrm{line-to-line} \mathrm{voltage} \mathrm{is} 11.5 \mathrm{~V}$ peak or $8.131 \mathrm{~V}$ rms (for SBC) and $17.96 \mathrm{~V}$ peak or 12.69 V rms (for MCBC). Fundamental peak values and THD of Line voltage and Phase voltage of 3-phase ZSI with SBC and MCBC techniques are shown in Figure 7 and 9 respectively. It is observed from Figure 7 and 9 that for peak value of line voltage the simulated and experimental values are $11.01 \mathrm{~V}$ and $10.47 \mathrm{~V}$ (for $\mathrm{SBC}$ ) or $15.15 \mathrm{~V}$ and $13.92 \mathrm{~V}$ (for MCBC) whereas for peak value of phase voltage are $6.35 \mathrm{~V}$ and $6.095 \mathrm{~V}$ (for SBC) or $8.715 \mathrm{~V}$ and $7.83 \mathrm{~V}$ (for $\mathrm{MCBC}$ ). The desired fundamental peak value of line voltage and phase voltage for 0.8 modulation index with SBC and $\mathrm{MCBC}$ technique are $11.5 \mathrm{~V}$ and $6.64 \mathrm{~V}$ (for $\mathrm{SBC}$ ) or $17.96 \mathrm{~V}$ and $10.372 \mathrm{~V}$ (for MCBC) respectively. Thus, the experimental and simulated values obtained for both the techniques are satisfactory as compared to theoretical values. Similarly, experimental THD values for both the techniques are well consist with the simulated values.

\begin{tabular}{|c|c|}
\hline Parameter & Specification \\
\hline DC Supply $\left(\mathrm{V}_{\mathrm{dc}}\right)$ & $10 \mathrm{~V}$ \\
\hline Output frequency & $50 \mathrm{~Hz}$ \\
\hline Switching frequency & $1 \mathrm{kHz}$ \\
\hline $\mathrm{C}_{1}=\mathrm{C}_{2}=\mathrm{C}$ & $1000 \mu \mathrm{F}$ \\
\hline $\mathrm{L}_{1}=\mathrm{L}_{2}=\mathrm{L}$ & $2 \mathrm{mH}$ \\
\hline Modulation Index & 0.8 \\
\hline $\mathrm{R}_{\text {Load }}$ & $33 \Omega$ \\
\hline
\end{tabular}

Table 1. Simulated and Experimental Parameters of ZSI.

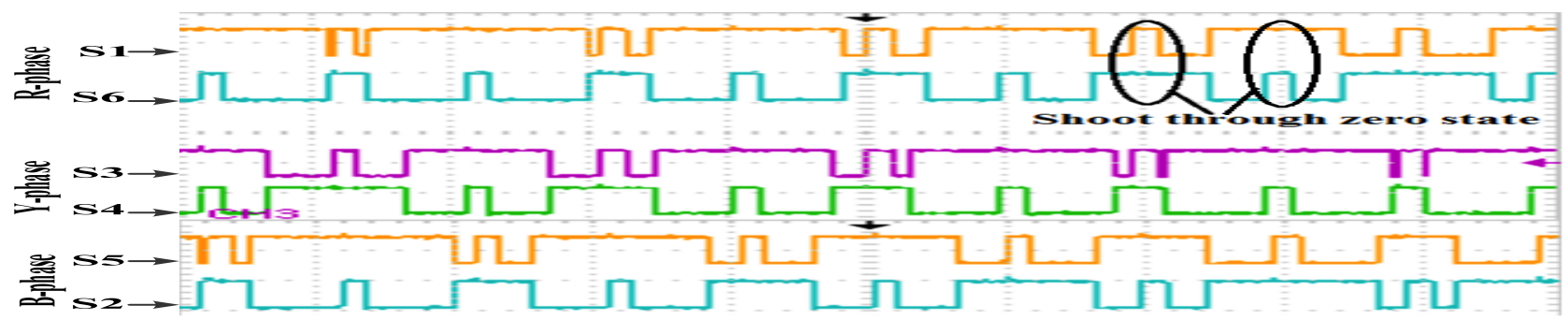

Figure 5: Experimental Waveforms for Controlling the 3-Phase ZSI

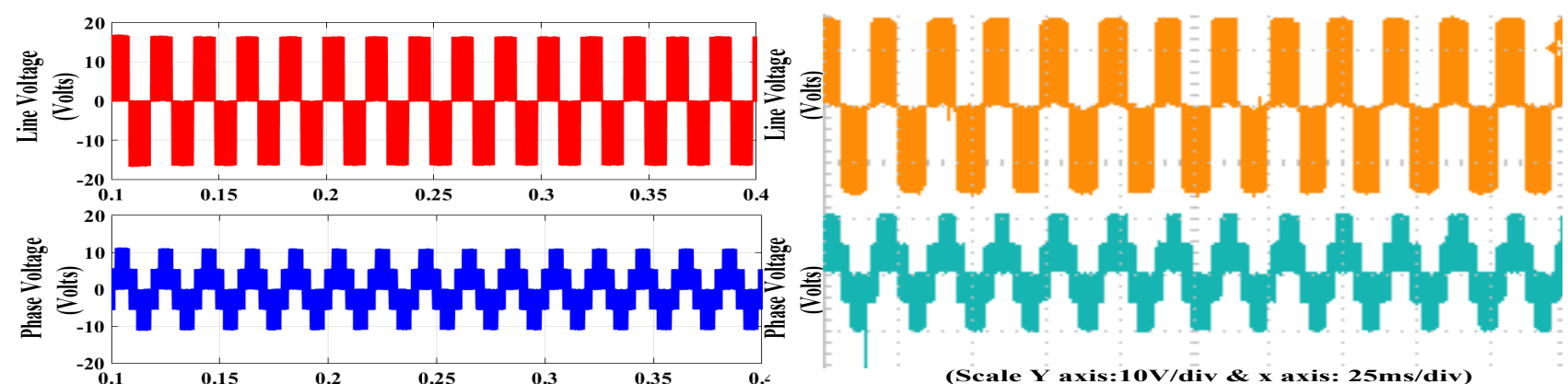

(a)

(b)

Figure 6: Line Voltage and Phase Voltage of 3-Phase ZSI for SBC Technique (a) Simulation and (b) Experimental with Modulation Index $=0.8$

(Experimental Scale $Y$ axis: $10 \mathrm{~V} / \mathrm{div} \& \mathrm{x}$ axis: $25 \mathrm{~ms} / \mathrm{div}$ ) 

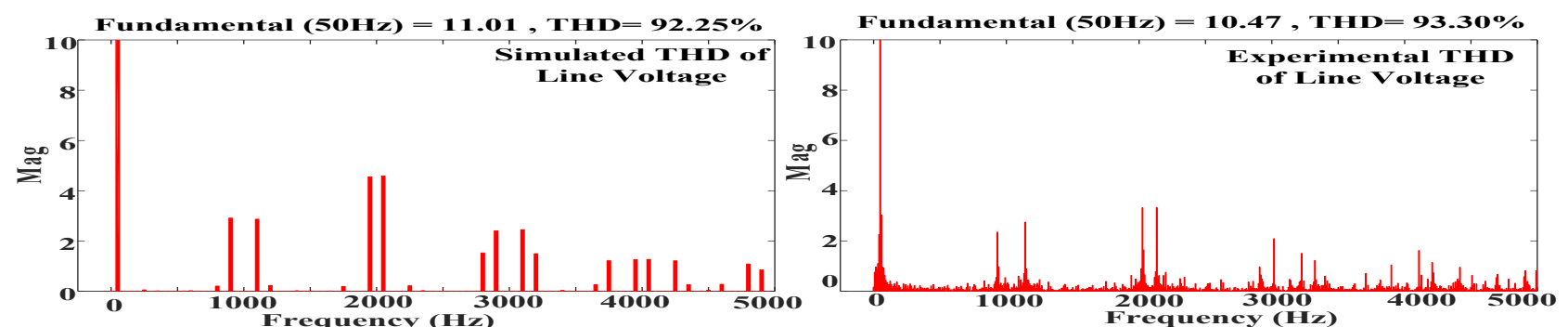

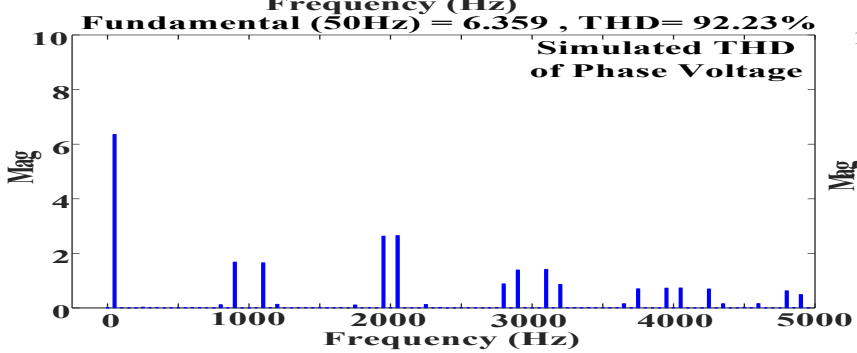

(a)

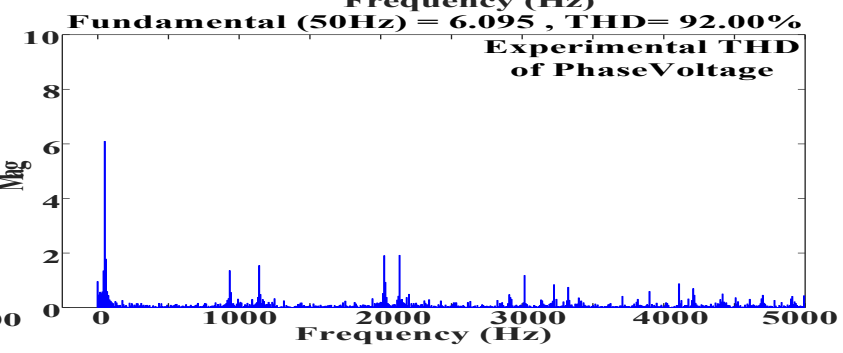

(b)

Figure 7: Fundamental Value and THD of Line voltage and Phase voltage of 3-Phase ZSI for SBC Technique (a) Simulation and (b) Experimental with Modulation Index $=0.8$

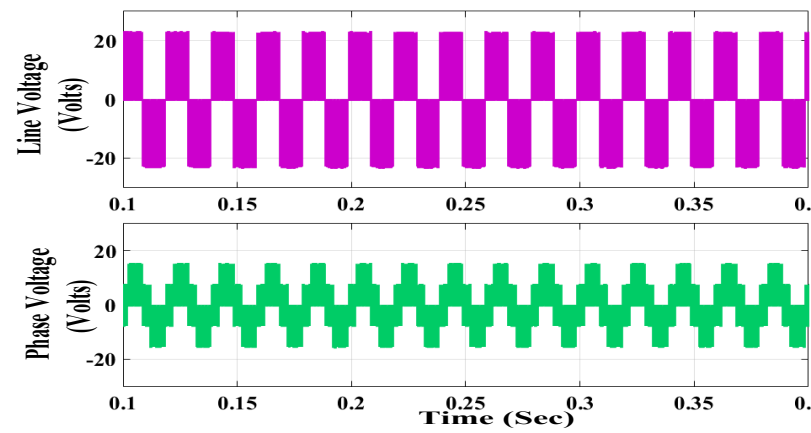

(a)
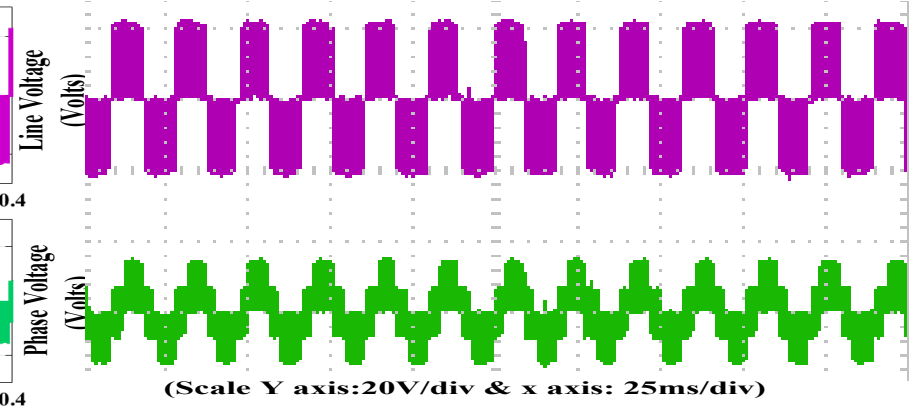

(b)

Figure 8: Line Voltage and Phase Voltage of 3-Phase ZSI for MCBC Technique (a) Simulation and (b) Experimental with Modulation Index $=0.8$

(Experimental Scale $Y$ axis: $20 \mathrm{~V} / \mathrm{div} \& \mathrm{x}$ axis: $25 \mathrm{~ms} / \mathrm{div}$ ) 

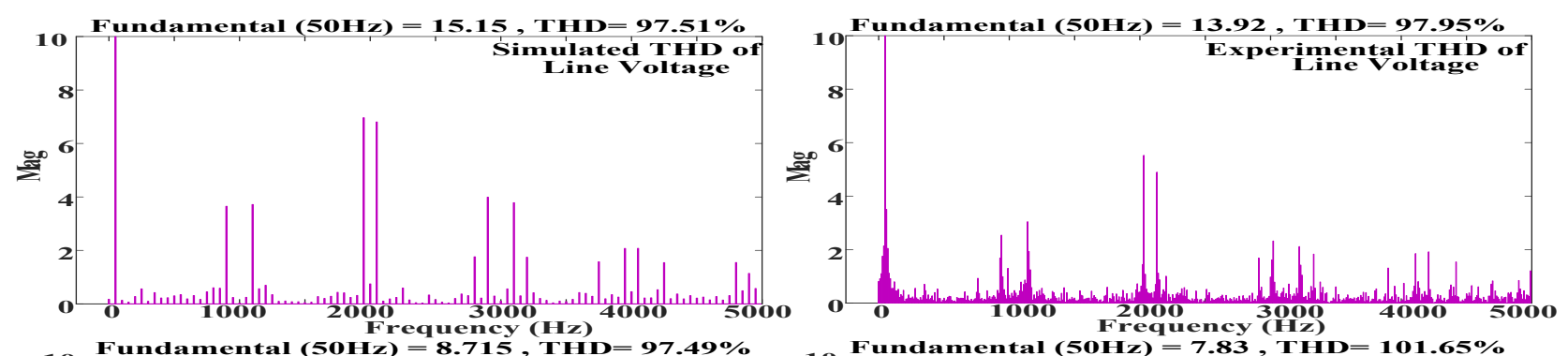

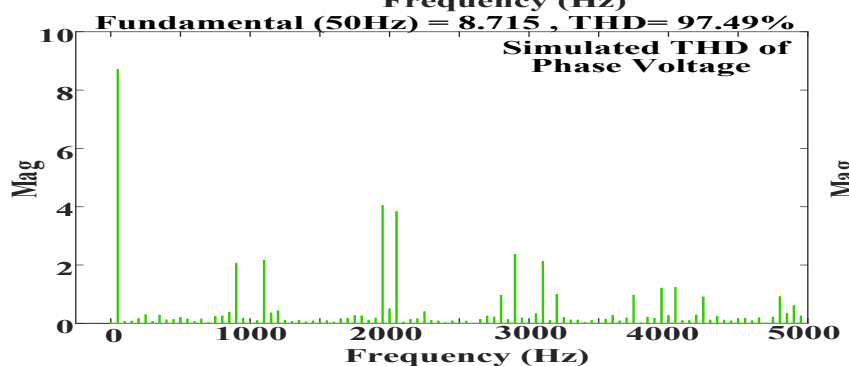

(a)

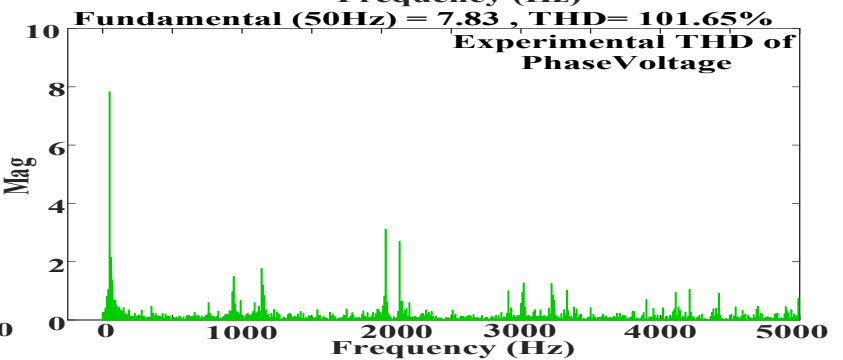

(b)

Figure 9: Fundamental Value and THD of Line Voltage and Phase voltage of 3-Phase ZSI for MCBC Technique (a) Simulation and (b) Experimental with Modulation Index $=0.8$

\section{Conclusion}

The control pulses for SBC and MCBC for Z-source inverter is generated using dsPIC33EP256MU810 and to validate this experimentation was performed. The experimental results shows that the fundamental rms of line \& phase voltage and THD are almost equal to calculated or simulated value with small error under tolerable limits. The experimentation was performed in laboratory at low voltage level. It is been observed that the boost is more in MCBC technique as compared to SBC with same modulation index in experimented results also. The DSC used is easy to program and control. The operating frequency of DSC used is $60 \mathrm{MHz}$; hence the computation time required is also less. With this advantage this DSC can be used for closed loop operation also. This can be further extended using PV panels as a dc source operating in closed loop.

\section{References}

Paper in a Journal:

[1] Nazmul Islam Raju, Md. Shahinur Islam, Ahmed Ahsan Uddin, "Sinusoidal PWM Signal Generation Technique for Three Phase Voltage Source Inverter with Analog Circuit \& Simulation of PWM Inverter for Standalone Load \& Microgrid System" International journal of renewable energy research nazmul islam raju et al., vol.3, no.3, 2013.

[2] I. Colak, E. Kabalci, "Developing a novel sinusoidal pulse width modulation (SPWM) technique to eliminate side band harmonics", International Journal of Electrical Power \& Energy System, Volume 44, Issue 1, January 2013 Elsevier, Pages 861-871. (Article)

[3] A.K. AI-Othman, Tamer H. Abdelhamid, "Elimination of harmonics in multilevel inverters with non-equal dcsources using PSO", Elsevier energy conversion and management, Volume 23, no. 1, pp. 19-26, 2008.

[4] F. Z. Peng, “Z-Source Inverter,” IEEE Trans. Industry Applications, Vol.39, pp.504-510, March/April 2003.

[5] Ankita Pande, G.N.Goyal, "Designing of impedance Network of Z-source Inverter for Different Control Methods," International Journal of Engineering Research and Application, April 2014, pp.23-27.

[6] M.-S. Shen, A. Joseph, J. Wang, F.Z. Peng, and D. J. Adams, "Comparison of traditional inverters and Zsource inverter for fuel cell vehicles," IEEE Trans. Power Electron., vol. 22, no. 4, pp. 1453-1463, Jul. 2007.

[7] Mahmooda Mubeen, “ Design Of Z-Source Inverter For Voltage Boost Application.” IJIREEICE- Vol. 4, Issue 2, February 2016.

[8] P. Sriramalakshmi And Sreedevi V. T, "Modified PWM Control Methods Of Z-Source Inverterfor Drive Applications.” ARPN Journal Vol. 10, No. 16, September 2015.

[9] F. Z. Peng, M. Shen, and Z. Qian, "Maximum boost control of the Z-source inverter," IEEE Trans. Power Electron., vol. 20, no. 4, pp. 833-838, Jul. 2005.

[10] M. S. Shen, J. Wang, A. Joseph, et al, "Constant boost control of the Z- source nverter to minimize current ripple and voltage stress", IEEE Trans. On Industry Applications, 2006, pp. 770-777. 
[11] Omar Ellabban, Joeri Van Mierlo and Philippe Lataire, “Comparison between Different PWM Control Methods for Different Z-source Inverter Topologies.” IR-ETEC, Pleinlaan 2, B-1050 Elsene Brussels, Belgium.

[12] Archana Kalyansundar and Rita Chattopadhyay, "Importance of Architecture Knowledge and Algorithm Redesign for Efficient DSP Programming” February 10, 2006.

[13] Mohan Renge, Hiralal Suryawanshi \& Madhuri Chaudhari (2015) "Digitally Implemented Novel Technique to Approach Natural Sampling SPWM, EPE journal, 20:1, 13-20,

DOI:10.1080/09398368.2010.11463744.

[14]Habib. Dallagi, Sami. Bouzaiane, "Implementation of the PWM Pre-calculated Technique for Elimination Harmonic Using Microcontroller" International Conference on Advanced Systems and Electric Technologies (IC_ASET),2017.

[15] PriyankaA. Kimmatkar, M. M. Renge, SonalKolse, PoojaBasutiya, - HPWM based control pulses generation for single phase qZSI using DSC\|, International Conference.

[16] Microchip datasheet on

a. dsPIC33EPXXX(GP/MC/MU)806/810/814and PIC24EPXXX(GP/GU)810/814.16-Bit Microcontrollers and Digital

Signal Controllers with High-Speed PWM, USB and Advanced Analog.

b. Microchip datasheet, DS70573-Introduction of microchip.

c. Microchip datasheet, DS70580-Oscillator and clock frequency selection.

d. Microchip datasheet, DS70645- High speed PWM.

Web site :- http://www.microchip.com

Book:

[17] Digital signal processing, C \& DSP processor assembly programming by N. G. Palan. 